(c) Hammond, John A., Lewis, Kenton, White, Helen and Bowman, Deborah (2012). The definitive, peer reviewed and edited version of this article is published in Widening Participation and Lifelong Learning, 13, 3, pp.45-59, 2012, http://dx.doi.org/10.5456/WPLL.13.3.45. 


\title{
Adjusting the Academy: Developing an Adjusted Entrance Criteria Scheme in a specialist Healthcare and Bioscience Higher Education Institution.
}

\author{
Author details \\ John A. Hammond \\ Principal Lecturer, Associate Dean (Widening Participation) \\ St George's, University of London \\ Cranmer Terrace \\ London SW17 ORE \\ j.hammond@sgul.kingston.ac.uk \\ +442087250320 \\ Kenton Lewis \\ Head of Widening Participation and Student Recruitment \\ St George's, University of London \\ Helen White \\ Widening Participation Officer \\ St George's, University of London \\ Deborah Bowman \\ Professor of Bioethics, Clinical Ethics and Law \\ St George's, University of London
}

\section{Abstract:}

Widening participation policies are commonplace in UK institutions and reflect a growing worldwide concern to redress social inequalities in higher education. Although policies may be common, the strategies employed to achieve this are varied. This paper describes the implementation of an adjusted A' Level criteria scheme in one programme at one HEI. Over a 4 year period, 34 out of 587 medical students entered under the adjusted criteria scheme. Results from this study indicate that although adjusted criteria students are more likely to fail at the first attempt there was no significant difference in examination results in the first and second years of study. Although small numbers, this study demonstrates the outcome of widening participation work that challenges assumptions that academic standards are dropping by admitting such students. The lessons learned from this approach are valuable irrespective of outcome in that it has encouraged innovative approaches in widening participation across the university.

Key words: Widening access, contextual data, social mobility, selection criteria, medical education 


\section{Introduction}

Most developed countries have seen a mass expansion of tertiary education since the turn of the $21^{\text {st }}$ century, yet there are still inequalities for under-represented groups internationally (Thomas \& Quinn, 2007). In the UK, during the period of New Labour government (1997-2010), education policies to widen participation were frequent (see for example, Higher Education Funding Council for England, 2006; Great Britain Department for Education and Skills, 2003; Higher Education Funding Council for England, 2003). Strategies used to widen participation during this period have varied dependent on factors such as type of Higher Education Institution (HEI) (traditional or new) or programme of study.

Medicine continues to be a highly selective profession with poor representation of some social groups. As a high status and well respected profession, medicine provides a lucrative career as well as high levels of social and cultural capital. This can make entering the profession are particular challenge for those from sectors of society where such capital is less prevalent. Evidence suggests that applicants to medical education are less likely to be black and minority ethnic (McManus 2004), or with parents with declared occupations of partly or unskilled nature. Such inequalities have not escaped government attention (Panel on Fair Access to the Professions, 2009), with greater calls to improve the diversity of the profession to reflect those patients to which they are providing healthcare (Mathers, Sitch, Marsh, \& Parry, 2011). In addition British medical university programmes have been the subject of high-profile controversy that extended beyond the pages of academic journals to national Tabloid newspapers (Coombes, 2008). With these issues in mind, access to medical education has been a priority (Angel \& Johnson, 2000) leading to diverse interventions (Dunkley, Dacre, Russell \& Greenhalgh, 2006; Kamali, Nicholson, \& Wood, 2005) and a range of strategies to widen participation (Beedham, Diston, Cottrell \& Drew, 2006).

Widening participation work can be categorised in a tripartite way, namely: i) raising aspirations; ii) facilitating admission; and iii) supporting and retaining students. Whilst there are some excellent research papers on widening participation in medicine (Greenhalgh, Seyan \& Boynton, 2004), we know little about whether widening participation 'works' (or even how to define and measure what 'works' means in this context (Do, Parry, Mathers \& Richardson, 2006)) or the progress of students who are described as 'widening participation' students. There remains significant underrepresentation of certain socio-economic groups in medicine (Department of Health [DH], 2004; British Medical Association [BMA], 2004); although the ways in which applicants are classified for the purpose of describing medical student demographics can be problematic (McManus, 2004). Personal identification with an elite profession (Kamali et al., 2005), financial considerations (Hilton \& Lewis, 2004), role models (McHarg, Mattick, \& Knight, 2007), family perceptions, life history, school support, maturity and peer response (Robb, Dunkley, Boynton, \& Greenhalgh, 2007) have all been recognised as significant in influencing potential applicants' decisions about pursuing a career in medicine. 
This paper describes the model and application of an 'adjusted criteria' (AC) scheme for considering $\mathrm{A}^{\prime}$ level ${ }^{1}$ results for admissions at a Higher Education Institution (HEI) specialising in healthcare and bioscience. In addition, this paper describes the demographics and the performance of the AC Scheme medical students in summative examinations taken in the first two years of the course as compared to their cohort. We were particularly interested in performance during the early years of the course because i) it has been argued that widening participation students find the transition to University study to be a time of disproportionate challenge (Arulampalam, Naylor and Smith 2004); and ii) success in the first two years of the course is required to progress to the predominately clinical years of training. It was felt therefore that it was essential to distil how students were performing in what are formative years. We explore the options for, and discuss the implications of, such an approach to widening access and participation. We recognise that the higher education context in which this approach sits has now changed with a global economic recession and a new coalition government. Therefore we will examine the findings in light of current education policy.

\section{The Adjusted A' Level Criteria Scheme}

In 2003, St George's, University of London (SGUL) developed a unique admissions policy whereby the entrance criteria for the 5 year MBBS (Bachelor of Medicine and Bachelor of Surgery) programme could be adjusted for candidates from schools with a significantly reduced examination track record. The underpinning principle on which the AC Scheme was based was a belief that treating unequal people equally was as unfair as treating equal people unequally. In the multi-factorial process of assessing an applicant's potential, we believed that an institution should take into account the extent of an individual candidate's efforts in achieving academic grades.

Therefore the AC scheme that we developed allows admissions tutors to consider the applicant's performance in context and in relation to their peer group, rather than the national average. A formula was devised to account for a student's performance in relation to the peer group with which he or she has studied. Where an applicant had predicted $\mathrm{A}$ ' Level grades ${ }^{2}$ below the standard offer of 'AABb'3, but above 'BBCb' and $60 \%$ higher than the average performance of his or her school (Department for Education, 2008), the applicant was guaranteed an interview. Following successful interview, a lower A' Level grade offer (to a minimum of BBCb) will be considered for candidates meeting the criteria of the adjusted grades scheme. In common with all applicants, candidates are still required to achieve their predicted grades. The rationale for the scheme that a student achieving BBCb at a poor performing school is achieving at an equal, or higher, level than a student attaining higher grades at a high performing school. It is important to note that it is only the grades that the applicant actually achieves (not the predicted grades) that are adjusted. Candidates are still required to take the subjects required for admission to medicine irrespective of the adjusted criteria. Furthermore they must also be successful at a blind interview where for reasons of fairness, interviewers do not have access to a candidate's academic record, as this has already been assessed as satisfactory in order for them to be called for interview. 
Importantly the AC scheme only considers A' level applications (which are the majority of applicants) and does not include the growing number applications from nontraditional entry qualifications that are considered at SGUL. Also this scheme does not use quotas or other socio-economic variables unlike other UK medical schools (Garlick \& Brown, 2008) nor are candidates treated any differently from other students. Those that are successful under the adjusted A' level criteria scheme join a standard five year MBBS programme and are neither distinguished nor offered any concessions or additional teaching sessions during their time studying but have access to the same, high level of learning support available to all students. This paper describes the academic progress of those students in four cohorts, from 2003/4-2006/7, who were admitted under the adjusted A' level criteria scheme. In short, this paper explores whether these students are, in the words of Hatt and Baxter (2003), able 'to play the academic game'.

\section{Evaluation}

\section{Data Collected for MBBS Students Admitted During the Period from 2003/4-2006/7}

A database was created using information routinely recorded and held centrally at St George's, University of London. The database contained data for each student who had enrolled on the 5 year MBBS programme since the AC scheme began in the academic year 2003/4. The data collected are shown in Figure 1 below.

\section{Insert Figure 1 here}

These data were anonymised, password protected and analysed in SPSS with advice from a senior statistician working in medical education research. When the project was conceived, a copy of the research protocol was sent to the local research ethics committee. The research ethics committee advised, via its Chair, that the project constituted an audit of the institutional widening participation policy and, as such, did not require formal review by the ethics committee.

The database distinguished between those students who had entered with lower grades from 'eligible' schools $(n=34)$ and those students who, based on the schools they attended, were 'eligible' for an adjusted offer, but in fact entered with the standard higher grades $(n=87)$. The comparison group consisted of students entering with the required standard higher grades who had attended schools that were not-eligible to participate in the AC scheme $(n=387)^{4}$. Table 1 below shows the total numbers of students entering via the AC scheme. Overall the proportion of students entering via the AC scheme over a 4 year period was small $(5.8 \%)$, and after an initial buoyancy, the numbers declined in the last two years (from $8.9 \%$ to $2.9 \%$ ).

Table 2 shows the ethnicity of students entering under the AC scheme. Although the total number of students of black origin is low over the 4 year period (17/587) the proportion entering under the $\mathrm{AC}$ scheme $(32 \%)$ is greater than students from white 
origin $(5.2 \%)$. This highlights that particularly poorly represented groups within medical school applicants, were more likely to enter under the AC scheme.

\section{Insert Table 1 here}

\section{Insert Table 2 here}

Other demographic data such as age, sex and socio-economic class were also compared, but were not found to have as marked differences as ethnicity and so are not reported on here.

\section{Comparing 'AC' Students and 'Non-AC' Students}

The study showed that the students who entered medicine via the A' level AC scheme perform as well on the course as their peers who come into medicine with the higher grades required for a standard offer. The performance of AC scheme students was compared with non-AC students both within each cohort and combining the four cohorts from the period of the study (2003-2007). Students who had withdrawn were recorded as missing in the results. Table 3 below shows the comparative pass rate achieved by AC and non-AC scheme students in summative examinations during the first year for all four cohorts including students who withdrew in the first year. A larger proportion of AC scheme students failed examinations on their first attempt (20.6\% compared with $14.1 \%)$. It is important to note that although there is a greater proportion the numbers are small $(n=7)$.

\section{Insert Table 3 here}

During the period of the study, the assessment scheme for the 5 year MBBS programme at St. George's was reformed which meant that students in the first two cohorts (2003-2004 and 2004-2005) were assessed differently from those in the later two cohorts (2005-2006 and 2006-2007). Students in cohorts 2005-2006 and 2006-2007 no longer received term-based summative examination results for years 1 and 2 .

In addition to noting the overall pass and fail rates, it was important to identify more precisely how the $\mathrm{AC}$ students were performing in summative examinations relative to non-AC students within their cohort. The changes to the scheme of assessment meant that the mean performance of students in the first two cohorts (i.e. under the old assessment system) had to be treated separately from those students in the later two cohorts (i.e. who were assessed under the revised scheme).

Table 4 below shows the mean scores of students in the first and second year by cohort. Students in the first two cohorts (2004-2005 and 2005-2006) had a separate mean mark for both first and second year summative examinations. Students in the second two cohorts (2005-2006 and 2006-2007) received a mean mark only for overall performance in the first two years. The findings demonstrate that the final mean mark for AC students in Year 1, Year 2 of the earlier cohorts and the combined result for latter cohorts was 
between 1 and $2.5 \%$ lower than the non-AC students. In each of the cohort means, the upper and lower bounds of the $95 \%$ confidence interval showed a wider spread for the AC students. Although this may be reflective of the small numbers, some AC students do better than their counterparts while others do not do as well.

\section{Insert Table 4 here}

For all 4 cohorts we were unable to examine whether there were any particular parts of the course where AC students performed differently from their non-AC scheme peers. The scheme of assessment is based on a cumulative marks achieved for themebased course work and it was not possible to break the results down to a comparable level of detail.

\section{Discussion}

The relationship between selection and eventual success in medical school is complex (Ferguson, James, \& Madeley, 2002). In determining admissions policies and making offers to candidates, a medical school should, of course, consider the expense of medical training and maximise the public investment. However, an institution should also reflect on its ethos and educational aims (Searle \& McHarg, 2003). Medical schools have a responsibility to encourage the widest range of well-qualified applicants both in the interests of equity and social justice (Mathers \& Lewis, 2008) and, although more controversially to some commentators (McManus \& Ip, 2008), to serve the diverse health needs of the population in a publicly funded health service. Recent findings suggest that the socioeconomic profile of the UK medical student population is not changing despite major initiatives designed to increase the demographic diversity (Mathers, Sitch, Marsh, \& Parry, 2011).

The adjusted A' level criteria scheme described in this paper has been moderately successful in widening access to medical school. The representation of applicants from state school, where performance is below the national average, has increased and candidates also come from an increased ethnic range. Indeed, a third of Black medical students, a group that is particularly under-represented in medical education and training (McManus, 2004), were admitted via the adjusted criteria scheme.

Despite the initially promising buoyancy of the scheme, the numbers of students recruited by these means reduced in the later 2 years reported here. The AC scheme has continued as a means of contextualised assessment at application, yet the number of applicants still remains low. This highlights how early enthusiasm depends on long-term commitment to ensure that widening participation measures are marketed, maintained and developed. The adjusted criteria scheme is well-publicised in widening participation activities such as summer schools and school visits and is flagged up in recruitment materials such as the prospectus and on the St George's University of London website (2011), to ensure that prospective applicants and, importantly, their teachers are aware of 
the initiative and how it works in practice. Equally it is important to appreciate that such applicants will always represent a relatively small proportion.

It is also the case that in a pre-qualification admissions process, as used for admission to all undergraduate programmes in UK HEIs, the AC scheme has to be based on predicted rather than actual grades. As the only medical school in the UK transparently operating a scheme of this type, those responsible for predicting A' level grades appear inclined to over predict performance in order to meet the requirements of the majority of medical schools, which means their students are less likely to benefit from the scheme. In a post qualification admissions system there would be less scope for such problems to exist however the appetite for structural alterations, which would involve a significant reshaping of both secondary and tertiary annual cycles, is not currently strong enough to enact such change.

Overall the scheme has the advantages of fairness and transparency. The use of nationally published data to evaluate the performance of schools is not perfect given the limitations of league tables. However it is consistent and each application is assessed individually to avoid targeting particular groups or charges of positive discrimination. Students who receive adjusted grade offers are not perceived as inferior to other candidates because the scheme is predicated on the belief that to perform $60 \%$ or more better than one's peers in an underperforming school demonstrates equivalent or greater potential than performing well in a more educationally advantaged environment. The ethos of the adjusted criteria scheme is that performance is inevitably shaped and distorted by educational privilege and sometimes results in what has been memorably described as 'artificial intelligence' (Dimmock, 2008).

Furthermore, assumptions about which type of educational environment best prepares applicants for University study are worthy of interrogation. In an earlier report the Higher Education Funding Council for England concluded that "students from independent schools appear to consistently do less well than students from other schools and colleges, when compared on a like-for-like basis. For the most highly selective higher education institutions [we] find that students from Local Education Authority schools do consistently better than similar students from independent schools" (HEFCE, 2003). More recently in an attempt to level the playing field for students from disadvantaged schools, the Assessment and Qualifications Alliance (AQA) has announced a proposal that university applicants should be awarded or deducted 'points' on the basis of which school they went to (Garner, 2011). This has sparked much media attention and uses the adjusted criteria scheme investigated here as an example. We would advise caution and do not advocate that the scheme be applied across all aspects of higher education or indeed all programmes of study. Instead we do consider the adjusted criteria scheme may be one way of encouraging social mobility in a profession that needs to be representative of its patients.

Our study also demonstrated that there was no statistically significant difference between the early years' performance of students who enter medical school with lower grades from academically weaker schools and their peers who joined the course with 
higher grades and attended academically stronger schools. While a larger proportion of adjusted criteria scheme students fail examinations on their 1st attempt at examination, the difference is not statistically significant and there may be many variables at work on which we are unable to speculate as we do not have contextualised data. Although factors such as financial concerns requiring students to have part-time jobs, caring responsibilities and more diffuse social support networks are examples that are worth exploring in future research and we are currently undertaking work in this field.

Previous work by Arulampalam, Naylor and Smith (2004) has suggested that the attrition rate amongst medical students is strongly influenced by A' level grades, but our research found that students who entered under the adjusted criteria scheme neither performed differently nor had a higher attrition rate. Some writers have suggested that widening participation initiatives are of questionable economic value and may even 'lower standards' (McManus \& Ip, 2008). This study challenges claims that standards are lowered as a result of a proactive widening participation initiative that did not bring any additional burden or cost. Although the adjusted criteria students did not receive any extra learning or pastoral support, the question of whether widening participation students or non-traditional entrants should receive additional and particular support remains open with some commentators suggesting that targeted activities such as pre-admission summer schools (McClements, 2006) and 'top up' programmes (Walker, Matthew \& Black, 2004) can be valuable. Therefore one disadvantage of the adjusted criteria scheme is that students are not identified and provision of resources relies on students identifying a need, seeking out and requesting additional support. There is evidence to suggest that students from lower socio-economic groups have less self belief than their peers that may deter them from seeking support (Thorpe et al, 2007).

This study only covers the first two years of medical education at a single institution. Similar studies over multiple sites would be interesting but challenging methodologically given the plurality of admissions criteria, course designs and assessment strategies in UK medical schools. The research team is developing a qualitative study of AC scheme student performance and success in the later years which will contribute to an emerging and intriguing literature on stereotyping, particularly in relation to ethnicity, and clinical learning (Woolf, Cave, Greenhalgh \& Dacre, 2008; McManus, Woolf \& Dacre, 2008). Our work has also been adopted in other healthcare programmes such as physiotherapy and we are considering extending the use of contextual data to recognise other ways of considering potential in applicants to university. This fits into an institution wide review of admissions practices in light of new forms of contextual data being available through the centralised admissions system (UCAS) and commitments laid out in our Office for Fair Access (OFFA) approved Access Agreement (SGUL 2011).

The numbers of students entering the adjusted criteria scheme are small and therefore interpretation of the results and claims for statistical generalisability are difficult. However, each individual adjusted criteria student in this study would not have entered medical school via a standard A' level offer and the majority of these students have performed as well as their peers: a significant and noteworthy achievement and an 
achievement that has been nationally recognised in the Times Higher Education, City of London Dragon and Guardian Public Service Awards Schemes.

Finally it is important to position the findings of this study in the current political and higher education climate in the UK. Implementing the findings of the Browne Review (Browne, 2010), the current coalition government have introduced strict access and retention targets to those institutions wishing to charge fees of more than $£ 6,000$ for new full-time undergraduate entrants in 2012-13 (Office for Fair Access, 2011). The government have also spelled out its' commitment to social mobility in the recent white paper 'Higher Education: Students at the Heart of the System' (Great Britain Department for Business, Innovation and Skills, 2011). Within the same paper, the government also announced plans to relax student number controls and allow unrestricted competition for A' Level students who achieve grades of AAB or higher. Such a policy places significant pressure on the AC scheme which, although working towards and supporting the social mobility agenda, runs contrary to any system which allows those HEIs who are taking in students with high grades to increase their student intake, and by extension increase their revenue. More broadly across widening participation activity within the UK HE sector, it is hard to see how this AAB policy, which offers a financial reward to HEIs that increase the proportion of their students with higher grades, is aligned to a social mobility agenda that encourages the consideration of contextual data on individual applications.

\section{Conclusion}

Widening participation needs to develop a robust research and evidence base. Much of the published work on widening participation offers either descriptive accounts of, often excellent, outreach initiatives and thought-provoking academic analyses of the prevailing deficit discourse, but, with notable exceptions (Holmes, 2002), there is limited work investigating outcomes of widening participation work. This small and modest study outlines the implementation of a transparent and imaginative grade adjustment scheme and illustrates how this has led to an increase in students not normally represented in university medical education. It also demonstrates that these students perform as well as their peers in summative examinations and represents the beginning of a programme of tracking the progression of these non-traditional pioneers in medical training. While the adjusted criteria scheme may be appropriate as a measure to address inequalities in medical programmes, those intending to implement such a scheme should approach with caution as 'one size does not fit all'.

\section{Acknowledgements}

We would like to acknowledge the students who have raised the profile of this work in mainstream media and other arenas. We would also like to acknowledge the support provided by Jennifer Poyser in the statistical analysis of the data and comments on early drafts of this report. There was no external funding for this research or conflicts of interest. 
Figure 1: Data collected for each student enrolling on the 5 year MBBS programme since 2003-2004

- Student ID number

- Age

- Sex

- Ethnicity

- Social and Economic Class (as defined by UCAS)

- A’ Level grades

- Previous school name

- Previous school average A' level score (at point of application)

- Exam results for each year of study at St. George's, scored on the first attempt

- Details of whether the student undertook an intercalated BSc degree*

* Intercalated BSc degrees are not available to all students, but are permitted depending on academic performance on the course. 
Table 1: Number of Adjusted Criteria Students on the 5 Year MBBS course

\begin{tabular}{|c|c|c|c|c|c|}
\hline & & & \multicolumn{2}{|c|}{ AC Status } & \multirow[t]{2}{*}{ Total } \\
\hline & & & $\mathrm{AC}$ & $\begin{array}{l}\text { Non- } \\
\text { AC }\end{array}$ & \\
\hline Year & $2003 / 2004$ & $\begin{array}{l}\text { Count } \\
\% \text { within Year }\end{array}$ & $\begin{array}{r}13 \\
8.9 \%\end{array}$ & $\begin{array}{r}133 \\
91.1 \%\end{array}$ & $\begin{array}{r}146 \\
100.0 \%\end{array}$ \\
\hline & $2004 / 2005$ & $\begin{array}{l}\text { Count } \\
\% \text { within Year }\end{array}$ & $\begin{array}{r}14 \\
9.5 \%\end{array}$ & $\begin{array}{r}133 \\
90.5 \%\end{array}$ & $\begin{array}{r}147 \\
100.0 \%\end{array}$ \\
\hline & $2005 / 2006$ & $\begin{array}{l}\text { Count } \\
\% \text { within Year }\end{array}$ & $\begin{array}{r}3 \\
1.9 \%\end{array}$ & $\begin{array}{r}153 \\
98.1 \%\end{array}$ & $\begin{array}{r}156 \\
100.0 \%\end{array}$ \\
\hline & 2006/2007 & $\begin{array}{l}\text { Count } \\
\% \text { within Year }\end{array}$ & $\begin{array}{r}4 \\
2.9 \%\end{array}$ & $\begin{array}{r}134 \\
97.1 \%\end{array}$ & $\begin{array}{r}138 \\
100.0 \%\end{array}$ \\
\hline Total & & $\begin{array}{l}\text { Count } \\
\% \text { within Year }\end{array}$ & $\begin{array}{r}34 \\
5.8 \%\end{array}$ & $\begin{array}{r}553 \\
94.2 \%\end{array}$ & $\begin{array}{r}587 \\
100.0 \%\end{array}$ \\
\hline
\end{tabular}


Table 2: Adjusted Criteria by Ethnicity

\begin{tabular}{|c|c|c|c|c|c|}
\hline & & & $\mathrm{AC}$ & tatus & Total \\
\hline & & & $\mathrm{AC}$ & Non-AC & \\
\hline Ethnicity & White Origin & Count & 12 & 200 & 212 \\
\hline & & $\%$ within & $5.7 \%$ & $94.3 \%$ & $100.0 \%$ \\
\hline & & $\%$ within AC & $35.3 \%$ & $36.2 \%$ & $36.1 \%$ \\
\hline & Black Origin & Count & 8 & 17 & 25 \\
\hline & & \% within & $32.0 \%$ & $68.0 \%$ & $100.0 \%$ \\
\hline & & $\begin{array}{l}\% \text { within AC } \\
\text { Status }\end{array}$ & $23.5 \%$ & $3.1 \%$ & $4.3 \%$ \\
\hline & Asian Origin & Count & 12 & 221 & 233 \\
\hline & & $\begin{array}{l}\% \text { within } \\
\text { Ethnicity }\end{array}$ & $5.2 \%$ & $94.8 \%$ & $100.0 \%$ \\
\hline & & $\begin{array}{l}\% \text { within AC } \\
\text { Status }\end{array}$ & $35.3 \%$ & $40.0 \%$ & $39.7 \%$ \\
\hline & Mixed Origin & Count & 0 & 24 & 24 \\
\hline & & $\begin{array}{l}\% \text { within } \\
\text { Ethnicity }\end{array}$ & $0 \%$ & $100.0 \%$ & $100.0 \%$ \\
\hline & & $\begin{array}{l}\% \text { within } \mathrm{AC} \\
\text { Status }\end{array}$ & $0 \%$ & $4.3 \%$ & $4.1 \%$ \\
\hline & Unknown or & Count & 2 & 91 & 93 \\
\hline & missing & $\begin{array}{l}\% \text { within } \\
\text { Ethnicity }\end{array}$ & $2.2 \%$ & $97.8 \%$ & $100.0 \%$ \\
\hline & & $\begin{array}{l}\% \text { within } \mathrm{AC} \\
\text { Status }\end{array}$ & $5.9 \%$ & $16.5 \%$ & $15.8 \%$ \\
\hline Total & & Count & 34 & 553 & 587 \\
\hline & & $\begin{array}{l}\% \text { within } \\
\text { Ethnicity }\end{array}$ & $5.8 \%$ & $94.2 \%$ & $100.0 \%$ \\
\hline & & $\begin{array}{l}\% \text { within } \mathrm{AC} \\
\text { Status }\end{array}$ & $100.0 \%$ & $100.0 \%$ & $100.0 \%$ \\
\hline
\end{tabular}


Table 3: Year 1 Pass and Fail Rates (all 4 cohorts 2003- 2006)

\begin{tabular}{|c|c|c|c|c|c|}
\hline \multicolumn{2}{|l|}{ AC Status } & \multicolumn{3}{|c|}{ Pass or fail full cohort } & \multirow{2}{*}{$\begin{array}{l}\text { Total } \\
\text { Pass }\end{array}$} \\
\hline & & Pass & Fail & Missing & \\
\hline \multirow[t]{2}{*}{$\mathrm{AC}$} & Count & 26 & 7 & 1 & 34 \\
\hline & $\begin{array}{l}\% \text { within AC } \\
\text { Status }\end{array}$ & $76.5 \%$ & $20.6 \%$ & $2.9 \%$ & $100.0 \%$ \\
\hline \multirow[t]{2}{*}{ Non-AC } & Count & 470 & 78 & 5 & 553 \\
\hline & $\begin{array}{l}\% \text { within } \mathrm{AC} \\
\text { Status }\end{array}$ & $85.0 \%$ & $14.1 \%$ & $.9 \%$ & $100.0 \%$ \\
\hline \multirow[t]{2}{*}{ Total } & Count & 496 & 85 & 6 & 587 \\
\hline & $\begin{array}{l}\% \text { within AC } \\
\text { Status }\end{array}$ & $84.5 \%$ & $14.5 \%$ & $1.0 \%$ & $100.0 \%$ \\
\hline
\end{tabular}


Table 4: Mean scores for the First Two Years of the Course

\begin{tabular}{|c|c|c|c|c|c|}
\hline & & $\mathrm{N}$ & Mean & \multicolumn{2}{|c|}{$\begin{array}{c}\text { 95\% Confidence Interval } \\
\text { for Mean }\end{array}$} \\
\hline $\begin{array}{c}\text { Year 1 final mark 03/04 } \\
\text { and 04/05 cohorts }\end{array}$ & $\mathrm{AC}$ & 26 & 65.08 & 61.46 & 68.69 \\
\hline & Non-AC & 263 & 66.61 & 65.54 & 67.68 \\
\hline & Total & 289 & 66.47 & 65.45 & 67.49 \\
\hline $\begin{array}{c}\text { Year 2 Final Mark } \\
\text { 03/04 and 04/05 cohorts }\end{array}$ & AC & 24 & 64.13 & 59.99 & 68.26 \\
\hline & Non-AC & 255 & 66.60 & 65.56 & 67.64 \\
\hline \begin{tabular}{c} 
Beund \\
\hline New Year 1 and 2- \\
anbined 06/07 cohorts
\end{tabular} & AC & 7 & 64.2907 & 60.3357 & 68.2456 \\
\hline & Non-AC & 287 & 65.0535 & 64.0018 & 66.1052 \\
\hline & Total & 294 & 65.0353 & 64.0063 & 66.0643 \\
\hline
\end{tabular}




\section{References}

Angel, C., \& Johnson, A. (2000) 'Broadening access to undergraduate medical education'. British Medical Journal, 321, 1136-1138.

Arulampalam, W., Naylor, R., \& Smith, J. (2004) 'Factors affecting the probability of first year medical student dropout in the UK: a logistic analysis for the intake cohorts of 1980-92'. Medical Education, 38, 492-503.

Beedham, C., Diston, A., Cottrell, D., \& Drew, C. (2006) 'Widening Participation in Medicine: The Bradford Leeds Partnership'. The Clinical Teacher, 3, 158-162.

British Medical Association. (2004) Demography of Medical Schools - A Discussion Paper. London, England: BMA Publishing.

Browne, J. (2010) Securing a Sustainable Future for Higher Education. An Independent Review of Higher Education Funding \& Student Finance (The Browne Review)

Coombes, R. (2008) 'BMJ in "smug docs" storm'. British Medical Journal, 336, 13401341.

Dimmock, P. W. (2008) 'Methinks the Professor Doth Protest Too Much'. British Medical Journal, 336, 1453-1454.

Do, P. C., Parry, J., Mathers, J., \& Richardson, M. (2006) 'Monitoring the Widening Participation Initiative for Access to Medical School: Are Present Measures Sufficient?' Medical Education, 40, 750-758.

Dunkley, L., Dacre, J., Russell, J., \& Greenhalgh, T. (2006) 'Widening Access to Medical School: Dick Whittington Summer School'. The Clinical Teacher, 3, 8087.

Ferguson, E., James, D., \& Madeley, L. (2002) 'Factors associated with success in medical school: systematic review of the literature'. British Medical Journal, 324, 952-957.

Garlick, P. B., \& Brown, G. (2008) 'Widening participation in medicine'. British Medical Journal, 336, 1111-1113.

Garner, R. (2011) 'Exam board to penalise private school pupils'. The Independent. 27 September 2011.

Great Britain Department for Business, Innovation and Skills (2011) Higher Education: Students at the Heart of the System. UK: Her Majesty's Stationery Office

Great Britain Department for Education and Skills (2003) The Future of Higher Education. London: HMSO.

Great Britain Department for Education (2011) School and College Performance tables. Retrieved from http://www.dcsf.gov.uk/performancetables (Accessed: 3 October 2011).

Great Britain Department of Health. (2004) Medical Schools: Delivering the Doctors of the Future. London, England: Department of Health.

Greenhalgh, T., Seyan, K., \& Boynton, P. (2004) "Not a university type": focus group study of social class, ethnic and sex differences in school pupils' perceptions about medical school'. British Medical Journal, 328, 1541-1544.

Higher Education Funding Council for England (2003) Schooling Effects on Higher Education Achievement. London, England: HEFCE 2003/32.

Higher Education Funding Council for England (2006) HEFCE strategic plan 2006-11. 06/13. 
Higher Education Funding Council for England (2003) HEFCE strategic plan 2003 2008. Retrieved from http://www.hefce.ac.uk/pubs/hefce/2003/03 35.htm (Accessed: January 21, 2007).

Hilton, S., \& Lewis, K. (2004) 'Opening Doors to Medicine'. British Medical Journal, 328, 1508-1509.

Holmes, D. (2002) 'Eight Years of Widening Access to Medical Education'. Medical Education, 36, 979-984.

Kamali, A. W., Nicholson, S., \& Wood, D. F. (2005) 'A Model for Widening Access into Medicine and Dentistry: The SAMDA-BL Project'. Medical Education, 39, 918-925.

Mathers, J., \& Lewis, K. (2008) 'Broadening Access to Medicine: Editorial Opposes Social Justice and Equal Opportunity’. British Medical Journal, 336, 1264.

Mathers, J., Sitch, A., Marsh, J.L., \& Parry, J. (2011) 'Widening access to medical education for under-represented socioeconomic groups: population based cross sectional analysis of UK data, 2002-6'. British Medical Journal, 341, d918

McClements, P. L. (2006) Tracking LEAPS Students Through Their Years in Higher Education: A South East Forum Funded Support. Retrieved from http://www.leapsonline.org/measuring_success.html [Accessed 27 September 2009].

McHarg, J., Mattick, K., \& Knight, L. (2007) 'Why People Apply to Medical School: Implications for Widening Participation Activities'. Medical Education, 42, 815821.

McManus, I. C. (2004) 'Measuring Participation in UK Medical Schools: Social Class Data are Problematic to Interpret'. British Medical Journal, 329, 800-801.

McManus, I. C., \& Ip, H. (2008) 'Increasing Diversity Amongst Clinicians'. British Medical Journal, 336, 1082-1083.

McManus, I. C., Woolf, K., \& Dacre, J. (2008) 'The Educational Background and Qualifications of UK Medical Students from Ethnic Minorities'. BMC Medical Education, 8, 21.

Office for Fair Access (2011) How to produce an access agreement for 2012-1. OFFA guidance to institutions. Retrieved from: http://www.offa.org.uk/universities-andcolleges/writing-an-access-agreement/ (Accessed: 31 May 2011)

Panel on Fair Access to the Professions. (2009) Unleashing Aspiration: The Final Report of the Panel on Fair Access to the Professions. London, England: Cabinet Office. Retrieved from http://www.cabinetoffice.gov.uk/accessprofessions

Robb, N., Dunkley, L, Boynton, P., \&, Greenhalgh, T. (2007) 'Looking for a Better Future: Identity Construction in Socio-economically Deprived 16 Year Olds Considering a Career in Medicine'. Social Science and Medicine, 65, 738-754.

Searle, J., \& McHarg, J. (2003) 'Selection for medical school: just pick the right students and the rest is easy!' Medical Education, 37, 458-463.

St George's, University of London. (2011) OFFA Access Agreement 2012-13. Available at http://www.offa.org.uk/accessagreements/searchresult/?inst=St\%20Georges\%20Hospital\%20Medical\%20School

St George's, University of London. (2011) Undergraduate Prospectus. http://www.sgul.ac.uk/undergraduate/ 
Thomas, L., \& Quinn, J. (2007) First Generation Entry Into Higher Education. An International Study. Maidenhead, UK: Open University Press

Thorpe, A., Snell, M., Hoskins, S. and Bryant, J. (2007) False Uniqueness: the selfperception of new entrants to Higher Education in the UK and its implication for Access - a pilot study. Higher Education Quarterly, 61 (1), pp. 3-22.

Walker, L., Matthew, B., \& Black, F. (2004) 'Widening Access and Non-completion: An Inevitable Link? Evaluating the Effects of the Top-up Programme on Student Completion'. International Journal of Lifelong Education, 23(1), 43-59.

Woolf, K. M., Cave, J., Greenhalgh, T., \& Dacre, J. (2008) 'Ethnic Stereotypes and the Underachievement of UK Medical Students from Ethnic Minorities: Qualitative Study'. British Medical Journal, 337, 611-615.

\footnotetext{
${ }^{1} \mathrm{~A}$ ' level qualifications in the UK are usually taken from the ages of 16-18 and usually comprise studying 4 subjects in the first year (denoted as "AS") and continuing with three subjects in the second year (denoted as "A2"). The full two year course of study is known as the A' Level. Students would therefore usually complete their A' Level study with three A2 grades (denoted by capital letters in the range A*-E) and one stand alone AS grade (denoted by a lower case letter in the range a-e).

${ }^{2}$ Predicted A' level grades are usually the grades predicted by the teacher directly involved in a student's education and based on the student's achievement at previous levels (eg GSCE and AS levels). This 'predicted grade' is one factor that universities to assess potential of potential applicants.

${ }^{3}$ The standard grades required to receive an offer of a place on the 5 year MBBS course at St George's, University of London were AABb at A/AS Level rising to AAAb for applicants in the 2008 admissions cycle.

${ }^{4}$ Students who entered with alternative qualifications, such as International Baccalaureate or undergraduate degrees, were excluded from the study
} 